\title{
MARXISMO HISTÓRICO-DIALÉTICO: QUESTÕES TEÓRICAS E METODOLÓGICAS
}

Adrián Sotelo V. ${ }^{1}$

\begin{abstract}
RESUMO:
O presente artigo discute a pertinencia metodológica e epistemológica do marxismo - e suas expressões no materialismo histórico e dialético - afim de compreender a dinâmica das trocas capitalistas e suas transformações nos fenômenos sociais e humanos no século XXI.

Palavras-chave: marxismo, dialética, totalidade, implicação da ordem, investigaçãoexposição.
\end{abstract}

\section{MARXISMO HISTÓRICO Y DIALÉCTICO: THEORETICAL AND METHODOLOGICAL ISSUES}

\section{RESUMENE:}

En el presente artículo se evalúa la pertinencia metodológica y epistemológica del marxismo -y de sus expresiones en el materialismo histórico y dialéctico- con el fin de comprender la dinámica de los cambios y de las transformaciones de los fenómenos sociales y humanos en el siglo XXI.

Palavras-chave: Marxismo, dialéctica, totalidad, orden implicado, investigaciónexposición.

\section{Introducción}

La crisis mundial del régimen general del capital, abierta casi al final de la primera década del siglo XXI, desencadenó un panorama teórico y de crisis que sumergió a la mayoría de las expresiones teóricas -o paradigmas que se conformaron en las décadas anteriores-, en un universo caracterizado por la vaguedad y las incertidumbres respecto al análisis y diagnóstico profundos, tanto de la crisis estructural del capitalismo como de las perspectivas de futuro que se abren para los trabajadores y la humanidad. En el fondo, esta situación "epistémica" se explica en virtud de la intensa sobredeterminación y hegemonía del pensamiento dominante cimentado en la ideología capitalista de mercado y en el egocentrismo individual como presuntos "motores" de la historia y de las sociedades humanas.

En la década de los noventa y en el primer lustro del Siglo XXI, el panorama es tremendamente desconsolador: las disciplinas sociales y las corrientes de pensamiento ligadas a él prácticamente se han fundido en el discurso neoliberal de libre mercado, del individualismo metodológico exacerbado y en un sociodarwinismo grosero mostrando 
impotencia para formular diagnósticos e hipótesis de investigación autónomos, que reflejen genuinamente la esencia de los fenómenos estudiados sin interferencia de los paradigmas eurocentristas y de los elaborados por la ideología norteamericana de fuerte contenido positivista y racista. Son éstos los que han tomado la batuta y quienes marcan las pautas de investigación y los contenidos académicos, utilizando para ello la influencia que ejercen a través del poder político y de los sistemas de becas a los estudiantes y de financiamiento de las instituciones de educación superior y de posgrado, así como de institutos y centros de investigación. Por eso es urgente recuperar la autonomía y la capacidad crítica del pensamiento latinoamericano para crear sus propios marcos epistemológicos y cuadros teóricos, así como métodos de investigación en un esfuerzo que dé por resultado la elaboración de conceptos y categorías propias que, a la par, sean fiel reflejo del metabolismo esencial de los fenómenos sociales y humanos que discurren en el mundo en el despuntar del Siglo XXI.

En este contexto si bien el materialismo histórico y dialéctico habían sufrido uno de sus grandes retrocesos al final de la década de los ochenta del siglo pasado y en el curso de los noventa, particularmente debido a los efectos ideológicos de la desintegración de la URSS y del fortalecimiento de la ideología neoliberal, sin embargo, comienza a emerger con fuerza frente a la crisis estructural del capital y de las ideologías dominantes como el principal paradigma y corriente del pensamiento crítico y revolucionario del siglo XXI para dar cuenta de la esencia de dicha crisis y de los caminos para superarla, al erigir nuevos espacios de reflexión y análisis para la construcción de una nueva sociedad alternativa a la capitalista y a sus modos de producción fincados en la propiedad privada, el mercado y la explotación de la fuerza de trabajo por el capital.

El presente artículo tiene como finalidad evaluar la pertinencia metodológica y epistemológica del marxismo y de sus expresiones en el materialismo histórico y dialéctico para comprender la dinámica de los cambios y de las transformaciones de los fenómenos sociales y humanos para impulsar su transformación.

La obra de Marx no se reduce a El capital, sino que hay que tomar en cuenta el conjunto de su producción literaria desarrollada, junto con Engels, a lo largo de su vida, compuesta por libros, cuadernos, notas, obras de distintas disciplinas, manuscritos, cartas. Para nosotros, ese es el camino correcto que se debe recorrer para entender su pensamiento en su rica totalidad — mirando el árbol, pero sin perder el horizonte del bosque-, con su carácter procesual y sus contenidos teórico-analíticos, metodológicos y lingüísticos.

Existen dos maneras de ver, analizar y seleccionar los textos de Marx, sobre todo sus obras fundamentales: de una manera parcial, selectiva o, como planteamos aquí, viéndolos como totalidad viva y en creciente evolución conceptual, categorial y analítica. Nos inclinamos por este último método porque nos asegura una lectura múltiple, variada y colorida de los textos, que se puede sistematizar alrededor de las hipótesis y mediante su propio desarrollo conforme éstas se comprueban a la luz de los acontecimientos históricos. De esta manera el pensamiento de Marx, y por extensión la epistemología del materialismo histórico y científico, no se puede dividir en "rebanadas ideológicas" ${ }^{2}$ o en "rupturas epistemológicas", como plantea Louis Althusser al dividir el pensamiento de Marx en cuatro grandes etapas. La primera es la "ideológica" o de las "obras de juventud", y se extiende desde la Tesis doctoral hasta los Manuscritos y la Sagrada Familia. La segunda, que es la 
etapa de las "obras de ruptura y transición", abarca las Tesis sobre Feuerbach y la Ideología alemana. La tercera está constituida por las "obras de maduración teórica": todas las obras posteriores a 1845 y las anteriores a los ensayos de redacción de El capital (1855-1857). Por último, la cuarta etapa abarca las "obras de madurez", y son todas las que escribió después de $1857 .^{3}$

El riesgo de hacer esta división del pensamiento de Marx es terminar por imaginar que hay un antagonismo entre lo "viejo" y lo "nuevo", y engendrar un tertium exclusum, produciendo un fantástico fenómeno de "suma cero" que en el mejor de los casos conduce a un callejón sin salida. Por el contrario, ese pensamiento (científico) se debe apreciar y analizar global, dialéctica y fluidamente en el contexto de una totalidad llena de categorías -es decir, como dice Marx, de formas de ser, de determinaciones de existencia- y de relaciones de todo orden (social, cultural, lingüístico, etc.) en constante evolución y desarrollo epistémicos tanto cuantitativos como cualitativos, de tal modo que lo nuevo se articule con lo viejo superándolo y produciendo una nueva totalidad. Por lo tanto, a nuestro juicio es un error oponer a Marx contra Marx, es decir, enfrentar como antagónicas la obra fundamental, El capital, con sus escritos previos, como los Manuscritos económicofilosóficos de 1844, Los cuadernos de París, La ideología alemana, La Miseria de la filosofía, El Manifiesto del Partido Comunista, Trabajo asalariado y capital, El Dieciocho Brumario de Luis Bonaparte, los Grundrisse (que de acuerdo con Román Rosdolsky constituyen la antesala de El capital ${ }^{4}$ ); la Contribución a la crítica de la economía política o La Guerra Civil en Francia. Cada uno de estos escritos posee su propio valor huerístico, analítico y autónomo en cuanto son producidos en condiciones y contextos históricos distintos. Pero al mismo tiempo, y he aquí su valor, están concatenados en una rica producción llena de significados, categorías, conceptos y proposiciones que son precisamente los que posibilitan la constitución de una verdadera corriente marxista (un sistema filosófico integral) en constante evolución, que emergió en el siglo XIX y se consolidó en el transcurso del XX.

El materialismo histórico es el esfuerzo teórico, metodológico y analítico para comprender la dinámica y las grandes transformaciones de la historia y de las sociedades humanas, que resulta de la aplicación de las categorías y conceptos de la dialéctica materialista bajo una concepción de totalidad y de orden implicado. ${ }^{5}$ Esta perspectiva separa al materialismo histórico de todas las formas y tesis de pensamiento ligadas a la preservación del orden existente y a las visiones dominantes de parcialidad que asumen la mayoría de las corrientes teórico-filosóficas de nuestros tiempos como el estructuralismo, el funcionalismo, el positivismo y sus subdivisiones temáticas.

La categoría de totalidad encierra una concepción de la realidad que la concibe como orden implicado, es decir, como totalidad integrada en la que las partes sólo se entienden y articulan en el todo y éste en sus partes dentro de una rica totalidad de relaciones productivas, sociales y humanas. Esta tesis es contraria al pensamiento dominante, pues afirma que las categorías del pensamiento son un fiel reflejo tanto de la "realidad externa" al hombre (el mundo empírico, la naturaleza) como de la historia, y que de ninguna manera constituyen categorías aisladas o eternas, como las de "globalización", "fin de la historia", "postcolonialismo", "democracia" o "posmodernidad" que pregonan las corrientes idealistas. 
En breve, para decirlo con Lenin:

El mundo exterior, reflejado en nuestra conciencia, existe independientemente de nuestra conciencia. Sólo esta solución materialista es compatible realmente con las ciencias naturales y sólo ella elimina la solución idealista de la cuestión de la causalidad, propuesta por Petzoldt y Mach. ${ }^{6}$

Es quizás en el Manifiesto, según Lenin, donde se expone de manera materialista "...la nueva concepción del mundo, el materialismo consecuente aplicado también al campo de la vida social, la dialéctica como la más completa y profunda doctrina del desarrollo, la teoría de la lucha de clases y el papel revolucionario histórico mundial del proletariado como creador de una sociedad nueva, de la sociedad comunista". ${ }^{7}$ De la misma manera, para Marx la dialéctica es "...la ciencia de las leyes generales del movimiento, tanto el del mundo exterior como el del pensamiento humano" (cit. por Lenin, op. cit., p. 31) y la ciencia de las contradicciones en la esencia misma de la materia. Por tanto, el materialismo histórico es la aplicación y extensión del materialismo al campo de los fenómenos sociales y humanos en una rica visión que contempla la totalidad en permanente cambio y transformación, Se combate, así, la estática de las ideas y tesis que pregonan las corrientes dominantes del pensamiento burgués y conservador. Diría Engels que lo único que no cambia y es inmutable, es el movimiento.: es éste el que, sobre la bases de contradicciones: tesis, antítesis y síntesis, explica el devenir de la historia, los grandes cambios humanos, las crisis y el surgimiento del nuevo orden social, Se pudo, así, descubrir el devenir de un orden social y humano asentado en formaciones sociales y económicas que, si bien en sucesión contradictoria y dependiente de las luchas de clases y de los Estados, constituyeron los principales sistemas de producción y modos de producir como el comunismo primitivo, el esclavismo, el socialismo y el capitalismo, esta última como la formación dominante.

El materialismo histórico proporcionó un método específico de análisis de estos fenómenos al postular, en el Prólogo a la Contribución a la Crítica de la Economía Política escrito en 1859 que:

"...en la producción social de su vida los hombres establecen determinadas relaciones necesarias e independientes de su voluntad, relaciones de producción que corresponden a una fase determinada de desarrollo de sus fuerzas productivas materiales. El conjunto de estas relaciones de producción forma la estructura económica de la sociedad, la base real sobre la que se levanta la superestructura jurídica y política y a la que corresponden determinadas formas de conciencia social. El modo de producción de la vida material condiciona el proceso de la vida social política y espiritual en general. No es la conciencia del hombre la que determina su ser sino, por el contrario, el ser social es lo que determina su conciencia. Al llegar a una fase determinada de desarrollo las fuerzas productivas materiales de la sociedad entran en contradicción con las relaciones de producción existentes o, lo que no es más que la expresión jurídica de esto, con las relaciones de propiedad dentro de las cuales se han desenvuelto hasta allí. De formas de desarrollo de las fuerzas productivas, estas relaciones se convierten en trabas suyas, y se abre así una época de revolución social. Al cambiar la base económica se transforma, más o menos rápidamente, toda la inmensa superestructura erigida sobre ella. Cuando se estudian esas transformaciones hay que distinguir siempre entre los cambios 
materiales ocurridos en las condiciones económicas de producción y que pueden apreciarse con la exactitud propia de las ciencias naturales, y las formas jurídicas, políticas, religiosas, artísticas o filosóficas, en una palabra las formas ideológicas en que los hombres adquieren conciencia de este conflicto y luchan por resolverlo. Y del mismo modo que no podemos juzgar a un individuo por lo que él piensa de sí, no podemos juzgar tampoco a estas épocas de transformación por su conciencia, sino que, por el contrario, hay que explicarse esta conciencia por las contradicciones de la vida material, por el conflicto existente entre las fuerzas productivas sociales y las relaciones de producción. Ninguna formación social desaparece antes de que se desarrollen todas las fuerzas productivas que caben dentro de ella, y jamás aparecen nuevas y más elevadas relaciones de producción antes de que las condiciones materiales para su existencia hayan madurado dentro de la propia sociedad antigua. Por eso, la humanidad se propone siempre únicamente los objetivos que puede alcanzar, porque, mirando mejor, se encontrará siempre que estos objetivos sólo surgen cuando ya se dan o, por lo menos, se están gestando, las condiciones materiales para su realización. A grandes rasgos, podemos designar como otras tantas épocas de progreso en la formación económica de la sociedad el modo de producción asiático, el antiguo, el feudal y el moderno burgués. Las relaciones burguesas de producción son la última forma antagónica del proceso social de producción; antagónica, no en el sentido de un antagonismo individual, sino de un antagonismo que proviene de las condiciones sociales de vida de los individuos. Pero las fuerzas productivas que se desarrollan en la sociedad burguesa brindan, al mismo tiempo, las condiciones materiales para la solución de este antagonismo. Con esta formación social se cierra, por lo tanto, la prehistoria de la sociedad humana".

Aplicando esta tesis del materialismo histórico tenemos que la crisis de agotamiento del patrón de reproducción del capital posbélico de mediados de los setenta -y el advenimiento de uno nuevo a partir de los ochenta del siglo pasado- se explica por una contradicción entre lo que Marx llamó el ser social con la conciencia social (o superestructura): una idea que, equivocadamente o por miopía acomodaticia, los críticos y los enemigos del marxismo tomaron al pie de la letra sin ver su dimensión metafórica, crítica y cualitativa ni, por supuesto, su carácter metodológico, que permite imaginar los rumbos de la investigación científica, que se desplazan desde lo abstracto a lo concreto y nuevamente a lo abstracto, para brindar una perspectiva de múltiples relaciones e interrelaciones de manera global, dinámica y creativa. ${ }^{8}$

De igual manera, en el Posfacio de 1873 a la segunda edición alemana de El capital, se descubre la diferencia existente entre el método de investigación y el método de exposición que, en el plano epistemológico, significa recorrer el camino de la abstracción a la concreción; es decir, diferenciar la investigación propiamente dicha de la exposición formal de los resultados en un discurso estructurado y homogéneo.

Plantea Marx en el Posfacio:

"...el método de exposición debe distinguirse formalmente del método de investigación. La investigación ha de tender a asimilarse en detalle la materia investigada, a analizar sus diversas normas de desarrollo y a descubrir sus nexos internos. Sólo después de coronada esta labor, puede el investigador proceder a exponer adecuadamente el movimiento real. Y si sabe hacerlo y consigue reflejar idealmente en la exposición la vida de la materia, cabe siempre la posibilidad de que se tenga la impresión de estar ante una construcción a priori". 
En la Introducción general a la crítica de la economía política de 1857, Marx ilustra este método de la siguiente manera:

"Cuando consideramos un país dado desde el punto de vista económico-político comenzamos por su población, la división de ésta en clases, la ciudad, el campo, el mar, las diferentes ramas de la producción, la exportación y la importación, la producción y el consumo anuales, los precios de las mercancías, etcétera. Parece justo comenzar por lo real y lo concreto, por el supuesto efectivo; así, por ejemplo, en la economía, por la población que es la base y el sujeto del acto social de la producción en su conjunto. Sin embargo, si se examina con mayor atención, esto se revela [como] falso. La población es una abstracción si dejo de lado, por ejemplo, las clases de que se compone. Estas clases son, a su vez, una palabra vacía si desconozco los elementos sobre los cuales reposan, por ejemplo, el trabajo asalariado, el capital, etc. Estos últimos suponen el cambio, la división del trabajo, los precios, etc. El capital, por ejemplo, no es nada sin trabajo asalariado, sin valor, dinero, precios, etc. Si comenzara, pues, por la población, tendría una representación caótica del conjunto y, precisando cada vez más, llegaría analíticamente a conceptos cada vez más simples; de lo concreto representado llegaría a abstracciones cada vez más sutiles hasta alcanzar las determinaciones más simples. Llegado a este punto, habría que reemprender el viaje de retorno, hasta dar de nuevo con la población, pero esta vez no tendría una representación caótica de un conjunto sino una rica totalidad con múltiples determinaciones y relaciones. El primer camino es el que siguió históricamente la economía política naciente. Los economistas del siglo XVII, por ejemplo, comienzan siempre por el todo viviente, la población, la nación, el estado, varios estados, etc.; pero terminan siempre por descubrir, mediante el análisis, un cierto número de relaciones generales abstractas determinantes, tales como la división del trabajo, el dinero, el valor, etc. Una vez que esos momentos singulares fueron más o menos fijados y abstraídos, comenzaron los sistemas económicos que se elevaron desde lo simple — trabajo, división del trabajo, necesidad, valor de cambio - hasta el estado, el cambio entre las naciones y el mercado mundial. Este último es, manifiestamente, el método científico correcto. Lo concreto es concreto porque es la síntesis de múltiples determinaciones, por lo tanto, unidad de lo diverso. Aparece en el pensamiento como proceso de síntesis, como resultado, no como punto de partida, aunque sea el efectivo punto de partida, y, en consecuencia, el punto de partida también de la intuición y de la representación".

Las múltiples relaciones y determinaciones dialécticamente constituidas de los fenómenos sociales y humanos, así como de los modos de producción y las formaciones sociales históricas, constituyen la categoría de totalidad, la cual es la premisa metodológica del materialismo histórico y del método científico en ciencias sociales.

De acuerdo con Lukács, históricamente la determinación esencial de la totalidad del ser social y de sus categorías esenciales (lenguaje, cultura, ética, cooperación y división trabajo) tiene su fundamento en el trabajo, ${ }^{9}$ porque éste "puede ser considerado como fenómeno originario (Urphänomen)". ${ }^{10}$ De la misma manera demuestra que el Urphänomen es el principio ontológico del proceso de hominización del ser humano.

Al respecto dice:

Con el trabajo está dada, pues, ontológicamente la posibilidad de evolución ascendente de esas capacidades [se refiere a las del hombre en los eslabones intermedios, que se transforman a sí mismos y a la naturaleza en el trabajo], como también la posibilidad de que el hombre las ejercite; ya por el trabajo, pero ante todo a causa de la metamorfosis de la adaptación meramente reactiva, pasiva del proceso de reproducción al ambiente. A través de la 
modificación consciente y activa de dicha adaptación, el trabajo se convierte, no sólo en un hecho en el que cobra expresión la nueva peculiaridad del ser social, sino también precisamente, de manera ontológica - en modelo de la forma del ser enteramente nueva. ${ }^{11}$

Este principio de hominización contiene en su seno determinaciones que, como semillas, van a germinar en otras determinaciones más complejas, tales como la cultura, el arte, la ciencia y el lenguaje humano en estadios superiores de su evolución. Así, "el trabajo, en este sentido, como mero productor de valores de uso, es sin duda el comienzo genético de la hominización del hombre, pero en cada uno de sus factores contiene tendencias reales que necesariamente conducen más allá de este estado inicial". ${ }^{12}$

Lukács refiere aquí que la adaptación del hombre a través del trabajo no sólo se dio en dirección del paso de lo instintivo a lo consciente - problema fundamental de toda psicología-, o en la mera adaptación a las circunstancias que determina-sobrepone la naturaleza (por ejemplo la influencia de los diversos tipos de clima, las características del suelo, el oleaje marino, el peligro animal, los terrenos pedregosos o las praderas, las tempestades, las lluvias, la configuración geológica), sino en circunstancias que han sido previamente elegidas y deseadas por el sujeto en permanente proceso de desarrollo y transformación. ${ }^{13}$ Un sujeto que se autorrealiza mediante el trabajo e ingresa, de este modo, al complejo mundo del ser social que él mismo creó. ${ }^{14}$

La Ontología del ser social de Lukács, Dialéctica de la naturaleza de Engels, los Grundrisse y El capital de Marx son obras esenciales del materialismo histórico y de la categoría de totalidad como herramienta metodológica primicia de toda investigación y análisis social. Choca contra la parcialidad y la fragmentación del conocimiento y supera la unidimensionalidad de las ciencias sociales académicas que son incapaces de concatenar, como diría Marx, la esencia de los fenómenos con su apariencia ya que si coincidieran entonces toda ciencia, todo conocimiento, serían superfluos.

En síntesis, en el materialismo histórico la teoría y el método son indisolubles: se enfocan al objeto de estudio donde éste puede ser "aislado" sólo por cuestiones de investigación pormenorizada, nunca separado de su esencia y de la totalidad a la que el fenómeno obedece. Los otros elementos, es decir, la teoría y sus categorías y conceptos, así como el procedimiento metodológico son únicos e indivisibles: se limitan a exponer los resultados de la investigación científica de manera lógica y ordenada en una rica visión de totalidad que sintetiza lo abstracto y lo concreto, lo universal y lo particular. Si bien la población puede ser un punto de partida, ella, a la vez, es un punto de retorno; pero no de cualquier retorno; mecánico: por el contrario, su regreso implica la superación de la apariencia y, como dice Kosik, de la pseudoconcreción para ofrecer verdaderos resultados esenciales de las relaciones que la constituyen y determinan.

Y este proceder teórico-metodológico debe ser siempre una norma en el análisis social de cualquier "fenómeno parcial" para aprehender sus múltiples determinaciones y complejidades que acaecen y se profundizan con la evolución de la naturaleza y de la humanidad.

El objetivo del marxismo y del materialismo histórico es la superación de la parcialidad y de toda visión idealista y escatológica que oscurece la esencia y las posibilidades de transformación de la realidad y del orden social que la dialéctica materialista pone al 
desnudo afianzando sus posibilidades efectivas e históricamente viables de superación. Por el contrario las corrientes dominantes, hoy articuladas en al llamado "pensamiento único", se encargan de justificar y perpetuar a las sociedades de clase, en particular, a la sociedad capitalista. Cuestión que fue advertida por Marx en 1845 cuando, en su onceava tesis sobre Feuerbach, sentencia: "Los filósofos no han hecho más que interpretar de diversos modos el mundo, pero de lo que se trata es de transformarlo.

La transformación, el cambio, el movimiento son la esencia del materialismo histórico, sin los cuales se volvería superfluo para el pensamiento crítico y revolucionario.

Referências

Ernest Mandel, La formación del pensamiento económico de Marx. De 1843 a la redacción de El capital: estudio genético

Louis Althusser, La revolución teórica de Marx, Siglo XXI, México, 1976

${ }^{1}$ Véase Román Rosdolsky, Génesis y estructura de El capital de Marx. Estudios sobre los Grundrisse, Siglo XXI Editores, México, 1978.

${ }^{1}$ Para este tema véase: V.I. Lenin, Materialismo y empiriocriticismo, Ediciones en Lenguas Extranjeras, Pekín, 1975; David Bohm, La totalidad y el orden implicado, Barcelona, Cairos, 1987, 4 a Edición, particularmente "Introducción" (pp. 9-18) y Capítulo 1: "Fragmentación y totalidad" (pp. 19-52) y Karel Kosik, Dialéctica de lo concreto, Grijalbo, México, 1967

${ }^{1}$ V.I. Lenin, Materialismo y empiriocriticismo, op. cit., p. 89.

${ }^{1}$ Lenin, V.I., Marx, en OE, Vol. I, Editorial Progreso, Moscú, 1961, p. 26. Véase también: Carlos Marx y Federico Engels, Manifiesto Comunista, Editorial de Ciencias Sociales, La Habana, 2008, Edición a cargo de Ana Molina González; introducción y compilación de Isabel Monal.

${ }^{1}$ Carlos Marx, Prólogo de la contribución a la crítica de la economía política, p. 182.

Mi libro: Crisis capitalista y desmedida del valor: un enfoque desde los Grundrisse, coedición Editorial ITACA-UNAM-FCPyS, México, 2010.

${ }^{1}$ Lukács, György, Ontología del ser social: el Trabajo, Ediciones Herramienta, Buenos Aires, 2004, p. 55. 
${ }^{1}$ Ibid., p. 187. Al respecto Lenin considera que "La materia es lo primario; el pensamiento, la conciencia, la sensación son producto de un alto desarrollo. Tal es la teoría materialista del conocimiento, adoptada espontáneamente por las ciencias naturales", V.I. Lenin, Materialismo y empiriocriticismo, op. cit., p. 82.

${ }^{1}$ György Lukács, Ontología..., p. 100.

\footnotetext{
${ }^{1}$ Investigador del Centro de Estudios Latinoamericanos (CELA) de la Facultad de Ciencias Políticas y Sociales de la Universidad Nacional Autónoma de México (UNAM).
}

${ }^{2}$ Véase Ernest Mandel, La formación del pensamiento económico de Marx. De 1843 a la redacción de El capital: estudio genético, p. 181 y ss.

${ }^{3}$ Louis Althusser, La revolución teórica de Marx, Siglo XXI, México, 1976, p. 25.

${ }^{4}$ Véase Román Rosdolsky, Génesis y estructura de El capital de Marx. Estudios sobre los Grundrisse, Siglo XXI Editores, México, 1978.

${ }^{5}$ Para este tema véase: V.I. Lenin, Materialismo y empiriocriticismo, Ediciones en Lenguas Extranjeras, Pekín, 1975; David Bohm, La totalidad y el orden implicado, Barcelona, Cairos, 1987, 4 ${ }^{\mathrm{a}}$ Edición, particularmente "Introducción" (pp. 9-18) y Capítulo 1: "Fragmentación y totalidad" (pp. 19-52) y Karel Kosik, Dialéctica de lo concreto, Grijalbo, México, 1967

${ }^{6}$ V.I. Lenin, Materialismo y empiriocriticismo, op. cit., p. 89.

${ }^{7}$ Lenin, V.I., Marx, en OE, Vol. I, Editorial Progreso, Moscú, 1961, p. 26. Véase también: Carlos Marx y Federico Engels, Manifiesto Comunista, Editorial de Ciencias Sociales, La Habana, 2008, Edición a cargo de Ana Molina González; introducción y compilación de Isabel Monal.

${ }^{8}$ Carlos Marx, Prólogo de la contribución a la crítica de la economía política, p. 182. De igual manera, dos décadas y media de neoliberalismo mundial y vernáculo es la historia crítica de esa contradicción entre el viejo modo de vida, de producción y trabajo capitalista que se resiste a perecer (el antiguo Estado de bienestar: desarrollista, industrializador y fordista), y uno presuntamente nuevo, neoliberal, global, agresivo, excluyente, polarizante, anti-industrializador que se está afianzando a toda costa, incluso con la represión de los movimientos populares y sociales que se le oponen en cualquier parte del mundo. Véase también mi libro: Crisis capitalista y desmedida del valor: un enfoque desde los Grundrisse, coedición Editorial ITACA-UNAM-FCPyS, México, 2010.

${ }^{9}$ Lukács, György, Ontología del ser social: el Trabajo, Ediciones Herramienta, Buenos Aires, 2004, p. 55. 
${ }^{10}$ Ibid., p. 59.

${ }^{11}$ Ibid., p. 40.

${ }^{12}$ Ibid., p. 187. Al respecto Lenin considera que "La materia es lo primario; el pensamiento, la conciencia, la sensación son producto de un alto desarrollo. Tal es la teoría materialista del conocimiento, adoptada espontáneamente por las ciencias naturales", V.I. Lenin, Materialismo y empiriocriticismo, op. cit., p. 82.

${ }^{13}$ György Lukács, Ontología ..., p. 100.

${ }^{14}$ Ibid., p. 102.

Recebido dia 10/03/2010

Avaliado dia 20/05/2010 